\title{
Active learning in higher education as a restorative practice: a lecturer's reflections
}

\section{Dr Emma Roberts}

Leeds Trinity University, UK

\section{Abstract}

The critique of the 'sage on the stage' approach to university teaching is particularly relevant for applied fields such as business management where a 'guide on the side' approach can instead encourage more active participation from students. A module on People Management for second year degree students was modified to involve a greater proportion of student-centred, active learning activities relative to lectures and supported by the participatory mechanisms offered by Restorative Practice. This paper offers a reflection on how developing higher education ( $\mathrm{HE}$ ) pedagogy towards reducing reliance on lecturer defined content shifts both students and lecturers out of their comfort zone. The process of students moving towards greater responsibility seems to require points of abandonment in which a hiatus occurs between student expectation of tutor support and the realisation that self-responsibility is required. In the current context of greater measurement of student satisfaction in $\mathrm{HE}$, this poses a challenge for individual academics as well as universities. Disruptive and transformational learning experiences require relational support if they are to be successful and academic staff deserve appropriate development opportunities to become more aware and familiar with the new discomfort of the HE classroom.

Keywords: pedagogy; restorative practice; university learning and teaching; active learning; higher education. 


\section{Introduction}

Higher education has seen a shift away from the dominance of the lecture/tutorial and essay/exam style of teaching and assessment, the so-called 'sage on the stage' (King, 1993) towards active, cooperative or experiential learning (Cavanagh, 2011; Hermann, 2013). External pressures such as greater student numbers, prevalence of technology in the classroom, and the employability agenda have all driven an emphasis towards workrelated tasks and professional development of students alongside academic content (Leedham, 2009). Hagopian (2013, p.10) suggests that we need to rethink the structural architecture of learning and teaching within higher education (HE) when the 'millennial' students we are now facing increasingly question the 'structures of generational and intellectual authority'. This is perhaps especially relevant for business and management courses or other vocational courses where team work, cooperation and interpersonal skills are called for.

One of the challenges facing $\mathrm{HE}$ is to design learning environments in which students are actively involved in creating and constructing knowledge. Redesigning learning experiences to move towards student-centred learning is therefore likely to involve a broad range of tasks such as group work, short writing tasks, discussions, role-plays, simulations and games which are aimed at decreasing the role and prominence of teacher-centred activity and increasing student participation. Furthermore, this shift in emphasis from teacher to student is aimed at a higher level of engagement from the student and is also likely to be disturbing and uncomfortable. Zepke (2013) describes the transformations that occurs when students 'grapple with troublesome knowledge' as a result of being more actively engaged and emotionally committed to their learning:

Transformations though are unpredictable, neither teachers nor learners can know what spaces transformations will lead to. This provides an opening to question the current fashions of prescribing what students should have learnt by the end of a course. Such prescriptions could place unnecessary limits on learning. (Zepke, 2013, p.105)

Such a movement that challenges students in this way, but also reduces the reliance on the knowledge base of the academic, produces a far less comfortable experience. Indeed, the social-cultural model seems to necessitate discomfort on the part of both student and 
lecturer, as we move beyond the cosiness and self-esteem of our existing expertise. Cocreating knowledge alongside students' demands a preparedness to be uncomfortable and ignorant' (McWilliam, 2008, p.268). The shift to a new form of teaching and learning style is likely to present challenges to both students and academic staff in coping with the new demands. The teacher vacating central stage creates a vacuum for all involved and we might ask various questions about what students do, how they manage social interaction, how they manage quality, as well as what new demands are made of the teacher.

Creating such a space within a learning experience may well facilitate Vygotsky's (1978) 'zone of proximal development' i.e. what does the student need to learn next? Students can usefully occupy this learning space as the teachers, facilitators, researchers for each other and thereby learn more than they could learn on their own (Quay, 2003). Nonetheless, as a course leader introducing these practices to a student group, such underlying mechanisms are not clearly visible and need supporting and explaining.

Lange (2004) reports on a study of adult learners and their learning experience through the lens of transformational learning. She notes the disorientating experience of transformation depends on some stability and restoration to occur in order for the learner to 'survive' this disequilibrium. She conceptualises this as the 'dialectical nature of transformative and restorative learning' (2004, p.135). This is a very useful way of understanding the role of specific group support practices in the learning process. If the intention is to change students, not just provide them with knowledge, then such disruption needs the guidance of relational support:

The dialectic of transformational and restorative learning is vital, for it affirms that transformation is not just an epistemological process involving a change in the worldview and habits of thinking; it is also an ontological process where participants experience a change in their being in the world including their forms of relatedness. (Lange, 2004, p.137)

In sum, university learning and teaching strategies that promote 'decentering the teacher' [sic], encouraging students to take greater responsibility, and 'destabilising student assumptions about one-way intellectual power' (Hagopian, 2013, p.13), needs to also consider how support and guidance is provided systemically and structurally. In seeking practical tools to address some of these issues, the approach and language of Restorative 
Practice was explored as a framework for the student-centred element of learning and assessment.

In this paper, I reflect on the process of designing and implementing various changes to typical assessment and learning methods in line with ideas of the 'flipped classroom' and social learning through group activities (Quay, 2003; Biggs and Tang, 2009) which involved the use of screen-casting (Udell, 2005) to free up class time for student-centred group work rather than teacher-centred lectures. Given the shift in emphasis from tutor to student, there are attendant challenges for both parties in re-negotiating this new learning landscape. Therefore, I introduced a Restorative Practices approach as an underpinning framework that offers some practical techniques for facilitating communication, dealing with conflict, and as a way of involving all participants in an inclusive and engaged learning environment.

\section{Restorative Practices (RP) framework}

Restorative Practice (RP) has its roots in restorative justice that aims to repair relationships between victim and offender (Braithwaite, 1989) rather than simply be a punitive and punishment-based response. More recently, the inclusiveness of the approach has seen Restorative Practice develop strongly in school settings where teachers are encouraged to learn new ways of responding to students which actively engages them rather than simply punishing bad behaviour. It has hitherto been little recognised as a useful approach within higher education.

One of the most useful conceptualisations this approach offers is to focus on the reengagement of learners, suggesting that this might be achieved by changing the actions of those in power:

Restorative practices support specific androgogical philosophies, both at an organizational level and in the classroom, in a manner that seeks to engage and empower learners while de-emphasizing the expert model of education centred on authority figures. Restorative practices offer participatory mechanisms to engage adults who have been conditioned to be passive learners. (Adamson and Bailie, 2012, p.150) 
This has been referred to as doing things WITH students rather than TO them or FOR them based on the terminology of the Social Discipline Window (Costello et al., 2009). While this model refers to discipline within a younger education environment, the language remains a powerful descriptor of certain elements of HE practice.

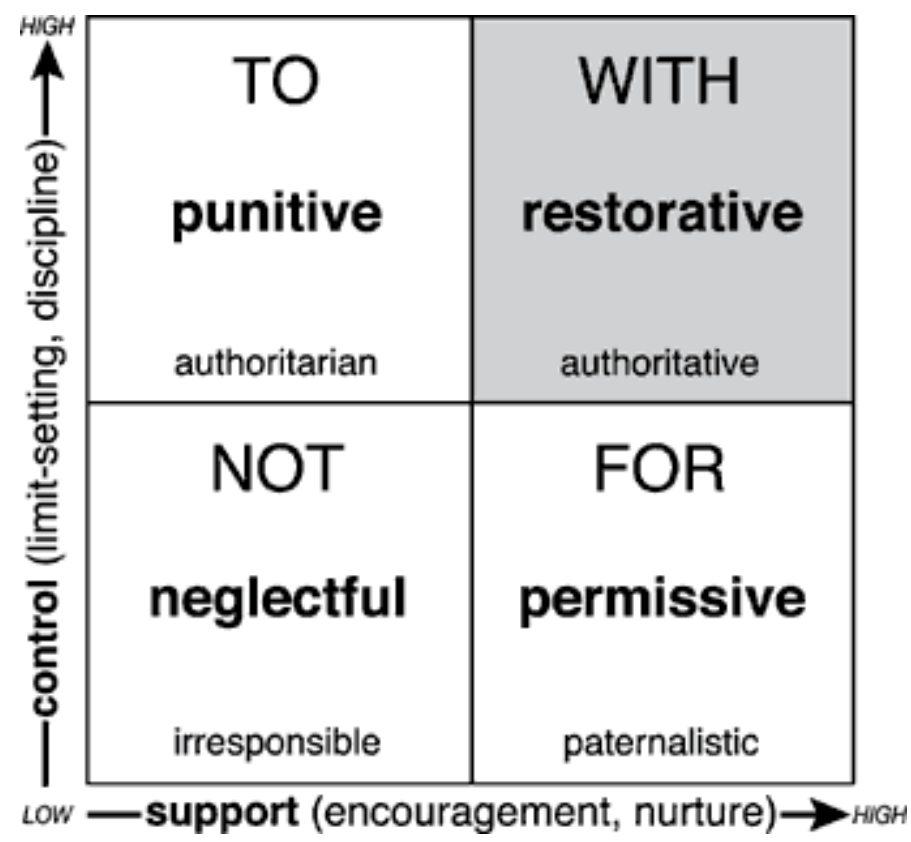

\section{Figure 1. Social Discipline Window (Wachtel and McCold, 2004).}

The 'restorative' element of this practice has now become a way of approaching a variety of fields: restorative practices in the workplace (Davey, 2007); restorative rhetoric of politics (Griffin-Padgett and Allison, 2010); restorative design (Yudelson, 2008); as well in the criminal justice arena e.g. Circles of Support and Accountability (Hanvey et al., 2011); and schools (Macready, 2009), to the extent that entire cities such as Leeds are aiming to become a Restorative City (Finnis, 2014). However, this movement has not appeared to make much impact on $\mathrm{HE}$, with relatively little attention being paid to the potential benefits in engaging under-graduates and other mature learners in restorative learning environments. There is significant discussion of the use of restorative justice to address misconduct issues (Kara and MacAlister, 2010) and yet little specifically assessing the use of Restorative Practice within the learning environment. Adamson and Bailie (2012) argue that Restorative Practice could have a significant impact on how students and academics view learning and growth, and that more research is needed into the impact of Restorative Practice on adult students and classroom environments. 
What is provided by this framework is a series of concrete practices that can be used as and when the group feel they need it. In the context of challenging and complex tasks set for groups studying business and management disciplines, this is not designed to be further support that is directed and driven by the tutor but initiated and conducted by the groups of students themselves. Restorative Practice as a model refers to a spectrum of possible actions from the formal to the informal such that small issues can be dealt with spontaneously, while larger issues can be resolved with the required time and diligence (Wachtel and McCold, 2004).

A crucial aspect of the whole spectrum of techniques is the need to express one's own affect and feelings such that the other person understands the impact that their behaviour is having on others. Towards the formal end is the group or 'circle' and this is the specific restorative practice embedded into the learning experience examined in this paper:

Circles are a more formal restorative process... A class, a group of students or a group of adults meet in a circle to discuss, answer questions, solve problems, play a game or offer feedback. A circle has a structure, purpose, and focus. It may be proactive or responsive. The topic may be personal, academic or workrelated. Circles may be the most adaptable form of restorative practices on the continuum. (Costello et al., 2010, p.13)

Two key elements of the circle process are focused on here: the 'talking stick' approach of listening to each person in turn, and the 'restorative questions' which focus attention on what is happening and what needs to be done next. The basic premise of the circle format is its egalitarian nature and the ability for all to be seen and heard. This basic feature is enhanced by encouraging opening questions which help people to get to know each other and to hear the quiet ones and dominating ones equally. Additionally, when things go wrong, the set of restorative questions from the International Institute for Restorative Practices (www.IIRP.edu) help to focus on what has happened and how it has affected each person. It concludes with specific actions that should happen next in order to resolve the issue.

The focus of this study was to explore the take-up and use of restorative practices among a second year student group in approaching their group assignment. The research questions were: How does the student group use restorative practices in their independent 
group assignment? What are student perceptions of the efficacy of the restorative practices adopted?

\section{Student experience}

This is a reflection of a second year core module on People Management for students on under-graduate business and management programmes into which Restorative Practices were introduced as a possible group process. The 30 students on the course were allocated to five mixed-ability groups by the tutor and these groups formed the seating arrangements for each classroom session for the duration of the course. The subject content aimed to cover both general line management competencies as well as an overview of the Human Resource Management function and its processes and techniques. Students were informed that Restorative Practices was one way dealing with people management and that therefore the experience of the group-work element of the course was as relevant as the 'book-knowledge' they may read about.

The two key processes of circle-time and restorative questions were introduced to the group early in the semester and initial group tasks structured by the tutor such that each group felt reasonably experienced in the process before being set the assessed work. Nonetheless, the time spent on instruction and guidance on this approach was fairly limited to the following two slides and two, half-hour sessions of circle-time.

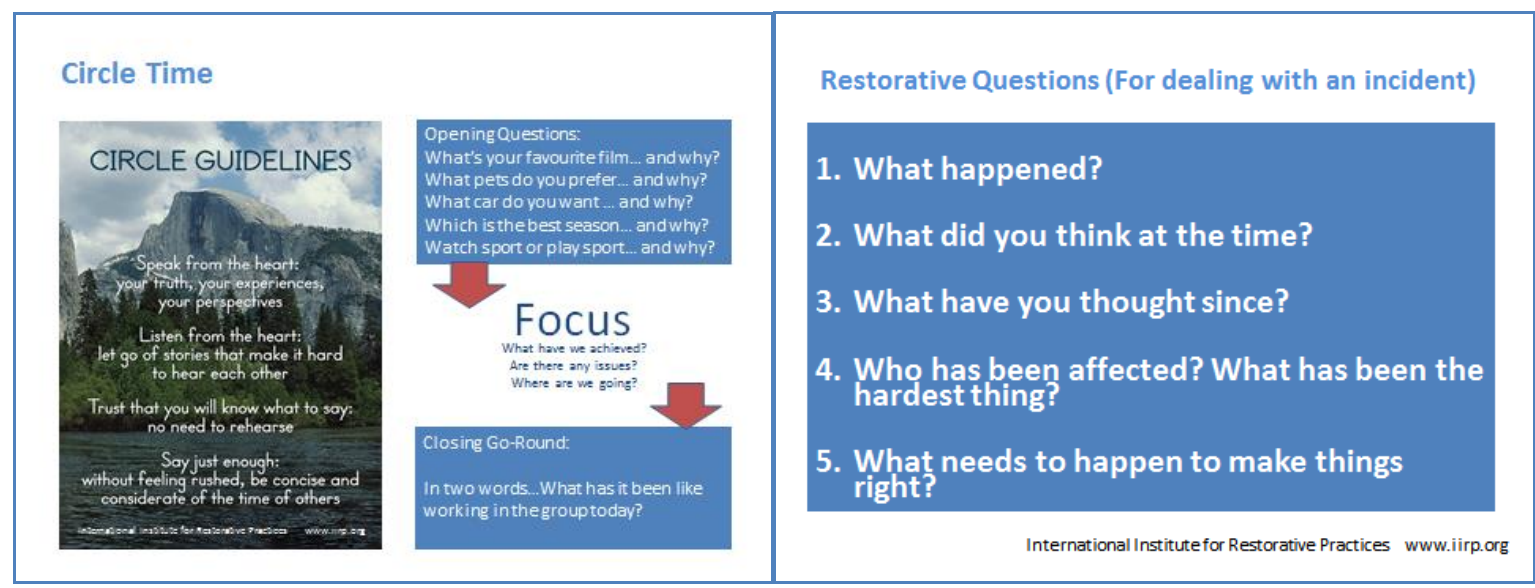

Figure 2. (C) 2010 International Institute for Restorative Practices: Wachtel, T. (2013) Defining restorative. Retrieved from http://www.iirp.edu/what-is-restorativepractices.php 
The groups were then given contemporary issues to explore in which they should design and conduct a primary research data collection project, and produce a group presentation. This was the first time the students were exposed to primary research design and was a deliberately challenging task to be completed over three weeks.

Following the assessed presentation, students were asked to write reflective reports on two critical incidents that occurred during the group experience, recounting their reflections on people management. This student experience of the module was developed in line with the learning and teaching strategy that sought to encourage student centred-learning. Further to this, departmental ethical approval was given to invite all students in the group, after the assessment stage, to participate in a short questionnaire of open questions on the impact of Restorative Practice on their group, and to take part in an independently facilitated focus group. Ten students responded to the questionnaire and seven students volunteered to be in the focus group.

The actual usage of Restorative Practices techniques in managing the group process was mixed but some students clearly felt empowered to use the techniques of Restorative Practice to resolve specific difficulties. It has also been noticeable that some students have reflected on the process as having longer term benefits, beyond resolving the actual incident or dispute:

This was a good experience in learning how to deal with people and to figure out a reasonable solution before firing them, which is what could have easily happened in a real business. (Reflection, 13)

Nonetheless, while the Restorative Practice techniques were seeking to develop a peer-topeer process, there were significant preferences for leadership from either the elected team leader (who was then expected to use their authority) or from myself as tutor:

I felt as though it wasn't as useful as it could have been... the group found it difficult. Maybe because it was due to the fact nobody wanted to upset one another. I think this wouldn't have been the case in a workplace as normally a manager or team leader sets up this type of meeting, heads it and is paid to do this particular job, to manage. (Reflection, 1) 
In the event of trying to implement such changes on the group, students also experienced futility and impotence when attempted leadership or group management failed to make the desired impact on other students:

I mean, I arranged a team meeting and no-one turned up. So what can I do? You can't say right all of you have lost five marks, what can you do? (Focus Group, 8)

Here it is clear that the use of Restorative Practice techniques to express the impact on the group and agree outcomes has not always worked and some students wish to have clear cut authority within the team. The sense of 'what can you do?' seems to be a resignation and resistance to actively judging others' contributions and a willingness to agree sanctions and consequences. Enforcement and authority seemed to be the fall-back preference for issues of under-performance and was especially evident in the focus group discussion.

\section{Lecturer's experience}

From the tutor perspective, the student dissatisfaction with the lack of authority being provided was distinctly uncomfortable. While there was some recognition from students that this was a 'real world' type assignment that was realistic for future employability, there were plenty of very specific suggestions about what the tutor should have done differently: the type of assessment; the grading system; the group allocation; and the marking criteria. The specific feedback was therefore focused not on the effectiveness of peer-to-peer support but framed as a failure of the tutor. It appeared that the preferred solution was not for a better peer system but for more authority being used or delegated by the tutor. There was discernible pressure on me to take more of an active, even authoritarian, role and it continued to be uncomfortable to resist this pressure throughout the process. Individual students came to me for advice, asked for suggestions on how to deal with a peer, and made plaintive requests for more input into their group. Was this abandoning my role as teacher if I turned their question around and placed responsibility back on them?

I was also very aware of the current political climate of student satisfaction being of key importance. I was acutely aware of competing pressures to deliver transformative learning 
environments and yet protect student satisfaction at the same time. I was left with questions around the comfort and discomfort of learning environments and whether student 'comfort' is a necessary feature of HE in an era of marketisation of university education.

One aspect of this Restorative Practices framework is the social discipline window which focuses on the varying levels of support and control provided to students. Certain aspects were firmly under control of the tutor such as allocating students to groups, setting the brief, grading judgements and failing students for non-attendance, all of which can be seen as forms of control. Other aspects, also firmly under the control of the tutor, were about providing support to students such as delivery of lectures, activities and guided reading. It can be seen that these elements were satisfying, routine and comfortable for students. Traditional tutor-centred activities could be characterised as 'doing things TO and FOR' students and it appears that these are essentially satisfying and in accordance with student expectations that the tutor will take ultimate responsibility. Both authoritarian and paternalistic approaches seem to be accepted by students as the norm within the HE learning context.

The content and structure of what student groups did in their own time in preparing for assignments were not overseen by the tutor and were entirely under student control, and they seemed willing to use the suggested techniques of Restorative Practice. While not all groups reported its use, it seems that some students were willing to take on board the structure and guidance of tutor-led content (such as Restorative Practice techniques) and seek to institute it into their own independent practices with mixed results. The Restorative Practice frame suggests that students were able to model the practices introduced by the tutor under supportive situations such as initial supervised tasks, perhaps an instance of 'doing things WITH students' again a positive experience characterised by an 'authoritative' tutor.

The question I am left with is whether these were independently managed by students without tutor control or support - framed in the 'NOT' quadrant of the social discipline window - and characterised as the tutor being perceived as 'neglectful' or 'irresponsible'. The reflections on this learning experience suggest that the difficulty for some students arises when peer-to-peer processes are not immediately successful and where peers fail to respond to student-led structure. This waiting period in which the group seeks to 'figure 
out a solution' appears to be anxiety provoking for some even though it is also stimulating. On reflection, this point of hiatus, when perhaps student satisfaction in the process hits an all-time low, is possibly the crucial cross-over point of student responsibility. It may be that such times of assessment focused anxiety are the crucibles in which the very skills of graduate-ness and employability are forged. And yet, this may come at a cost. Is there perhaps some loss of faith in the very academic who has structured this learning experience which some students in the group perceive as 'abandonment'?

Restorative Practice does not operate free of context, and where students are educated into relying on the judgement of the tutor then there is bound to be tension at the juncture between two systems. The process recommended by Hagopian (2013) that students develop their own authority includes a suggestion to accept student discomfort and a degree of anxious self-consciousness, but this leaves the question of how academic staff both provide the structure and cope with this discomfort themselves. The most surprising revelation as a tutor experimenting with this type of learning and teaching is the levels of student discomfort that the tutor needs to manage. Furthermore, 'this uncomfortableness must be honoured, and then usefully folded back into learning' (Hagopian, 2013, p.15).

There are two specific points of tension that this experience highlights. Firstly, in the political context of students being treated as consumers and continually asked for feedback and satisfaction ratings, any activities perceived as offering low support and low tutor control are perhaps likely to receive poor ratings for student satisfaction. Secondly, in an education system where students are sometimes passive recipients of a transmissive style of delivery, the openness and discomfort of the classroom without authority poses epistemological challenges for students. What is knowledge if I have to make it all up myself?

Nonetheless, despite the issues and tensions, students in the short, ten-week module did learn to use and experiment with Restorative Practice techniques with training and experience. It has been seen that they used it spontaneously to resolve specific issues and found some success. This was a new and unexpected active learning experience that these students were exposed to and the fact that it was found to be challenging and generated dissatisfaction from students is not to be unexpected. Rather, it has raised questions of how we prepare students to negotiate such uncomfortable learning environments and diminish their reliance on the relative safety of tutor authority. It also 
raises the tensions between grading and classification systems on which students rely for their employability prospects.

Yeah the learning is really going to help me in the actual work, my only point is that your grade is your foot in the door, once you get to work then all the skills you learn at university come into place then and that's where this specific exercise will become really advantageous. (Focus Group, 14)

This reminds us that students are keenly aware of what 'real' learning is and how useful it is for their future employability but are nonetheless caught up in the system of chasing grades and degree classification. Again wider, structural questions are posed by the fitness of the academic system for preparing students adequately beyond a mere intellectual grading system.

\section{Concluding remarks}

This module delivered an active, student-centred learning experience in which knowledge has been created in participation with others. One of the aims for these business students is to generate authentic experiences of management-related communities of practice. The idea is to provide challenging experiences which literally changes the individual's approach to a typical management situation. The hope then is that the individual would face the next challenge in a qualitatively different way: perhaps more empowered and active. The final interjection as the focus group closed illustrated this precise point:

I do think if we had to do this again, we'd all do it so much better - group laughter (Focus Group, 10)

My reflections on this experience have also asked what does it demand of the academic whose career has been built upon milestones of knowledge and expertise? There are numerous issues to be faced in dealing with a shift away from a system that privileges a knowledge base and towards a more liquid concept of learning. One of the problems suggested here is that the individual academic must also face that moment of perceived abandonment in which students realise that they must grapple with this knowledge alone. 
In these moments, some students reach out for further support, cling to familiar strategies, and are perhaps understandably resentful of the 'neglectful' teacher.

This suggests that HE must build in greater structures of support for both students and lecturing staff. Disruptive and transformational learning experiences require relational support if they are to be successful and academic staff deserve appropriate development opportunities to become more aware and familiar with the new discomfort of the $\mathrm{HE}$ classroom. For learning practices such as these to be restorative then both students and staff need ways of dealing with the shift in responsibility that has occurred. Then there is a possibility opened up for academic staff to become learners themselves through this encounter and for students to accept and embrace responsibility for their learning.

\section{References}

Adamson, C.W. and Bailie, J.W. (2012) 'Education versus learning: restorative practices in higher education', Journal of Transformative Education, 10(3), pp. 139-156.

Biggs, J. and Tang, C. (2009) Teaching for quality learning at university. London: Open University Press.

Braithwaite, J. (1989) Crime, shame and reintegration. New York: Cambridge University Press.

Cavanagh, M. (2011) 'Students' experiences of active engagement through cooperative learning activities in lectures', Active Learning in Higher Education, 12(1), pp. 23-33.

Costello, B., Wachtel, J. and Wachtel, T. (2009) The restorative practices handbook for teachers, disciplinarians and administrators. Pennsylvania, USA: International Institute for Restorative Practices.

Costello, B., Wachtel, J. and Wachtel, T. (2010) Restorative circles in schools: building community and enhancing learning. Pennsylvania, USA: International Institute for Restorative Practices. 
Davey, L. (2007) Restorative practices in the workplace. International Institute for Restorative Practices. Available at: http://www.iirp.edu/ (Accessed: 28 February 2016).

Finnis, M. (2014) Towards a restorative city, county, authority or community. Available at: http://www.restorativejustice.org.uk (Accessed: 28 February 2016).

Griffin-Padgett, D.R. and Allison, D. (2010) 'Making a case for restorative rhetoric: Mayor Rudolph Giuliani and Mayor Ray Nagin's response to disaster', Communication Monographs, 77(3), pp. 376-392.

Hagopian, K.J. (2013) 'Rethinking the structural architecture of the college classroom', New Directions for Teaching \& Learning, 2013(135), pp. 7-18.

Hanvey, S., Philpot, T. and Wilson, C. (2011) A community based approach to the reduction of sexual reoffending: circles of support and accountability. London: Jessica Kingsley.

Hermann, K. (2013) 'The impact of cooperative learning on student engagement: results from an intervention', Active Learning in Higher Education, 14(3), pp. 175-187.

Kara, F. and MacAlister, D. (2010) 'Responding to academic dishonesty in universities: a restorative justice approach', Contemporary Justice Review, 13(4), pp. 443-453.

King, A. (1993) 'From sage on the stage to guide on the side', College Teaching, 41(1), pp. 30-35.

Lange, E.A. (2004) 'Transformative and restorative learning: a vital dialectic for sustainable societies', Adult Education Quarterly: A Journal of Research and Theory, 54(2), pp. 121-139.

Leedham, M. (2009) 'From traditional essay to 'Ready Steady Cook' presentation: reasons for innovative changes in assignments', Active Learning in Higher Education, 10(3), pp. 191-206. 
Macready, T. (2009) 'Learning social responsibility in schools: a restorative practice', Educational Psychology in Practice, 25(3), pp. 211-220.

McWilliam, E. (2008) 'Unlearning how to teach', Innovations in Education and Teaching International, 45(3), pp. 263-269.

Quay, J. (2003) 'Experience and participation: relating theories of learning', The Journal of Experiential Education, 26(2), pp. 105-116.

Udell, J. (2005) 'Secrets of screencasting', InfoWorld, 27(20), pp. 34-34.

Vygotsky, L. (1978) Mind in society. Cambridge, USA: Harvard University Press.

Wachtel, T. (2013) Defining restorative. Available at: http://www.iirp.edu/what-isrestorative-practices.php (Accessed: 28 February 2016)

Wachtel, T. and McCold, P. (2004) 'From restorative justice to restorative practices: expanding the paradigm', IIRP's Fifth International Conference on Conferencing, Circles and other Restorative Practices. Vancouver, British Columbia, Canada 5-7 August.

Yudelson, J. (2008) The green building revolution. Washington: Island Press.

Zepke, N. (2013) 'Threshold concepts and student engagement: revisiting pedagogical content knowledge', Active Learning in Higher Education 14(2), pp. 97-107.

\section{Author details}

Emma Roberts (PhD, FHEA) is an Associate Principal Lecturer at Leeds Trinity University and programme leader for BA Business and Management. She is the Learning and Teaching Lead for the subject group and has research interests in innovative pedagogy in Higher Education, especially in the field of business and enterprise education. 